\title{
NUTRIÇÃO MINERAL DE MUDAS DE GRÁPIA (Apuleia leiocarpa) EM ARGISSOLO VERMELHO DISTRÓFICO ARÊNICO: (1) Efeito da dubaçio NPK no crescimento ${ }^{1}$
}

\author{
MINERAL NUTRITION OF YOUNG PLANT OF "GRÁPIA" (Apulew Ieiocwpa) IN A \\ PALEUDALF SOIL: (1) growth responso to NPK for tilization
}

Fernando Teixefra Nicoloso ${ }^{2}$ Marco Aurélio de Freitas Fogaça ${ }^{3}$ Flávio Zanchetti ${ }^{4}{\text { Evandro } \text { Missio }^{5}}^{5}$

\section{RESUMO}

A grápia (Apuleia leiocarpa Vog. Macbride) é uma espécie de grande interesse madeireiro, encontrando-se, atualmente, bastante dizimada devido â exploração extrativista, sem haver reposição através de reflorestamento. $O$ objetivo deste trabalho foi deter,ninar os níveis de adubação nitro genada, fosfatada e potássica no crescimento de plantas jovens de grdpia. As plantas foram cultivadas em vasos contendo $3,5 \mathrm{~kg}$ de um ARGISSOLO VERMELHO Distróflco arênico, em casa de vegeta çtlo. Foram avaliados 27 tratamentos, em esquema trifatorial completo (3x3x3), representados pela combinação de três níveis (0, 40 e 80mg kg') de $\mathrm{N}$, de $\mathrm{P}$ e de $\mathrm{K}$ na adubação. A análise do crescimento das plantas foi realizada mensalmente, através da altura da planta, di 2metro do caule e número de folhas remanescentes. Aos 140 dias após a emergência das plantas, avaliaram-se ainda o comprimento do sistema radicular, massa seca das folhas, do caule, de raízes e total da planta e a relação entre a massa seca das raízes e da parte aérea. A aduba ção fosfatada aumenta o crescimento das plantas em todos os pani metros avaliados, sendo que as maiores respostas, exceto para o comprimento do sistema radicular, ocorrem acima de $80 m g$ de $P$ $k_{5}$ '. A aplicação de K em doses superiores a áOmg kg', influencia positivamente o comprimento do sistema radicular, ndmero de folhas, altura da planta e massa seca da folha, do caule e total da planta. Por Outro lado, não altera o didmetro do caule, massa seca da raiz e a relação entre a massa seca das raízes e da parte aérea. O efeito benéfico da adubação nitrogenada, quanto ào comprimento do sistema radicular, número de folhas, altura de planta, massa seca de folhas e total da planta, é condicionada à aplicação conjunta de K. A grdpia demonstra ser uma espécie muito exigente em $P$ e medianamente exigente em $K$ e $N$ na fase inicial de crescimento, quando cultivada num ARGJSSOLO VERMELHO Distrtiflco arênico.

Palavras-chave: grápia, Apuleia leiocarpa, NPK, crescimento, nutrição mineral,fertilização.
SUMMARY

"Grápia" (Apuleia leiocarpa Vog. Macbride) is an important salive forest specie that lias been is extinction process. use abu of this study was to determine the optimum leveIs ai nitrogen, phosphonts, and potassium fertilization on the initial growth of grdpia. Grdpia plants were cultivated is pots containing 3,5kg of a Paleudalfsoil, under glasshouse condiuions. Twenty-seven fertilization treat,nenhs were used is a complete tr factorial scheme (3x3x3), represented by the combination of three leveis $\left(0,40\right.$, and $\left.80 \mathrm{mg} \mathrm{kg}^{\prime}\right)$ of $\mathrm{N}$, ei $P$, and ofIC $77 \mathrm{w}$ plant growth is height, stem diameter, and number of leaves were analyzed monthly. After 140 days o! cultivation other growth parameters were analyzed, as follow: dry weight of roots, stem, leaves, and o! the whole plant, rool/shoot dty weight ratio, and length of the root system. Phosphorus fertilization bscreases all evaluated growth parameters. and the highest raspasse, except for the length of the root .system, occurred above SOmg kg'. Potassiwn fertilization at doses greater dias $60 \mathrm{mg} \mathrm{kg}$ ' positivély affects several growth parameters, except for the root/shoot dry weight ratio, root dry matter, and lhe $51 \mathrm{~cm}$ diameter. $77 \mathrm{w}$ beneficial effectfrom the nitrogen fertiliration, as for the length of the root system, number of leaves, plant height, and lhe dry weight of leaves, and of the whole pIas:, depend os lhe addition of $K$. Young plants o! grdpia growin: is a Paleudalf soil show high response to $P$ and moderate response to $K$ and $N$.

Key words: grdpia, mineral nutrition, fertilization, Apuleia leiocarpa, NPK, growth.

\section{INTRODUÇÃO}

A grápia (Apuleia Ieiocarpa Vog. Macbride) é uma planta florestal nobre com variada

${ }^{1}$ Projeto financiado pela FAPERGS e CNPq.

${ }^{2}$ Engenheiro Agrônomo, PhD., Professor Adjunto do Departamento de Biologia, Centro de Ciências Naturais e Exatas (CCNE), Universidade Federal de Santa Maria (UFSM), 97105-900, Santa Maria - RS. E-mail: nicoloso@ base.ufsm.br . Autor para correspondência.

${ }^{3}$ Engenheiro Agrônomo, Mestre em Agronomia, UFSM.

${ }^{4}$ Acadêmico do Curso de Engenheria Florestal, UFSM, bolsista CNPq

${ }^{5}$ Acadêmico do Curso de Engenharia Agronômica, UFSM. 
utilidade. É uma espécie que apresenta ampla distribuição geográfica no território brasileiro, porém atualmente se acha bastante descontínua, devido à devastação intensa das matas e à falta de reposição através do reflorestamento (MAflOS \& GUARANHA, 1983).

No estado do Rio Grande do Sul, segundo BRASIL (1973), a área ocupada por esta espécie épequena, encontrando-se nas partes mais altas do noroeste do planalto, onde o solo é fértil, profundo e úmido, e em pontos esparsos na Depressão Central. $\mathrm{Na}$ região de maior dispersão, a grápia ocorre em solo LATOSSOLO VERMELHO Distrófico típico (solo Santo Ângelo), e também nos solos CHERNOSSOLO ARGILUVICO Fémco típico (solo Ciríaco) e NEOSSOLO L1TÓLICO Eutróflco chernossólico (solo Charrua).

Em plantios experimentais no estado do Paraná, CARVALHO (1994) observou que a grápia tem crescido melhor em solo com nível de fertilidade média a elevada, bem drenado e com textura franca a argilosa. Já NICOLOSO et al. (1999), estudando as exigências nutricionais de mudas de grápia pela técnica do nutriente faltante, em ARGISSOLO VERMELHO Distrófico arênico, observaram que a altura da planta, número de nós do caule, número de folhas, comprimetito do sistema radicular, massa seca da planta e a concentração de nutrientes nos tecidos da planta diminufram acentuadamente pela omissão de $\mathrm{P}, 5, \mathrm{~N}$ e $\mathrm{K}$ na adubação, tanto no horizonte A como no B do solo.

Um dos grandes problemas nà elaboração de programas de plantios florestais, principalmente com árvores nativas, é o escasso conhecimento acerca da auto-ecologia das espécies. Desse modo, para a grápia, com exceção do trabalho realizado por NICOLOSO et al. (1999), não existem quaisquer informações específicas sobre as necessidades nutricionais, sendo que a adubação e a correção da fertilidade do solo, utilizadas atualmente, são de caráter empírico.

O presente estudo foi desenvolvido com o objetivo de determinar os níveis de adubação nitrogenada, fosfatada e potássica no crescimento de plantas jovens de grápia (Apuleia leiocarpa Vog. Macbride) em ARGISSOLO VERMELHO Distrófico arênico, que ocorre na região denominada Depressão Central, no Rio Grande do Sul.

\section{MATERIAL E MÉTODOS}

O experimento foi instalado em novembro de 1997, na casa de vegetação do Departamento de Fitotecnia do Centro de Ciências Rurais, na Universidade Federal de Santa Maria (UFSM), RS.
Foram avaliados 27 tratamentos em esquema trifatorial completo $(3 \times 3 \times 3)$, em que os fatores consistiram da combinação de três níveis $(\mathrm{O}, 40$ e 80mg kg') de $\mathrm{N}$, de $\mathrm{P}$ e de $\mathrm{K}$ na adubação. $\mathrm{O}$ delineamento experimental usado foi de tratamentos inteiramente casualizados, com cinco repetições. Utilizaram-se, como unidades experimentais, vasos contendo $3,5 \mathrm{~kg}$ de terra fina seca ao ar e duas plantas, os quais foram submetidos a rodízio periódico para evitar algum efeito de localização na casa de vegetação.

A adubação foi feita através da aplicação de soluções preparadas para atingir as concentrações de nitrogênio, fósforo e potássio estipuladas para cada tratamento. As fontes de nutrientes foram $\mathrm{NH}_{4} \mathrm{NO}_{3}, \quad \mathrm{NH}_{4} \mathrm{H}_{2} \mathrm{PO}_{4}, \quad \mathrm{NaH}_{2} \mathrm{PO}_{4}, \quad \mathrm{KNO}_{3}, \quad \mathrm{KCI}$, $\mathrm{KH}_{2} \mathrm{PO}_{4}$. Acrescentaram-se $30 \mathrm{mg} 5 \mathrm{~kg}$ ' de solo, através de $\mathrm{Na}_{2} \mathrm{SO}_{4}$, necessários ao suprimento desse elemento às plantas, segundo indicado por NICOLOSO et al. (1999).

$\mathrm{O}$ solo de cultivo utilizado no experimento foi o ARGISSOLO VERMELHO Distrófico arênico, pertencente à unidade de mapeamento São Pedro, coletado de $\mathrm{O}$ a $65 \mathrm{~cm}$ de profundidade, correspondente ao horizonte $\mathrm{A}$, sob vegetação de campo nativo, no município de Santa Maria, RS. Como resultados das análises físicas e químicas do solo obteve-se: $11 \%$ argila (método do densímetro); $0,7 \%$ de matéria orgânica (oxidação em solução sulfocrômica a quente e determinação por espectofotometria com Crt ); pH 4,8 em água (1:1), pH SMP 54; 1, Scmoe $_{6}$ t' de Ai ${ }^{3}$ trocável; 6, $1 \mathrm{cmol} \sim$ t' de $\mathrm{H}+\mathrm{Al} \sim^{3} 43 \%$ de saturação com $\mathrm{Al} \sim^{3}(\mathrm{~m} \%)$, $25 \%$ de saturação por bases (V\%), 3,5cmol t' de CTC; $1,0 \mathrm{cmol} \sim$ t' de Ca ${ }^{2} \mathrm{O}, 6 \mathrm{cmol} \sim$ t' de $\mathrm{Mg} ; 8 \mathrm{mg}$ t' de P; 16mg t' de K; 41,3mg $E$ ' de Fe; $10,6 \mathrm{mg}$ E' de Mii; $1,6 \mathrm{mg} E^{t}$ de $\mathrm{Zn}$; e O,9mg t' de Cu. Para as determinações de $\mathrm{Ca}^{2}, \mathrm{Mg} \sim^{2}$ e $\mathrm{Al} \sim^{3}$ usou-se o extrator KCI $1 \mathrm{~N}$, de $\mathrm{P}$ e $\mathrm{K}$ o extrator de Mehlich $(\mathrm{HCI} 0,05 \mathrm{~N}+1125040,025 \mathrm{~N})$, de $\mathrm{Zn}$ e $\mathrm{Cu}$ o extrator $\mathrm{HC} 1 \mathrm{O}, 1 \mathrm{~N}$, de $\mathrm{H}+\mathrm{AP} \sim$ o extrator $\mathrm{CaOAc}$ $1 \mathrm{~N}$ a pH =7,0, de Mii extrator KC1 $1 \mathrm{~N}+\mathrm{HC} 1 \mathrm{O}, 1 \mathrm{~N}$ e de Fe o extrator oxalato de amônio O,2M a pH 3,0.

Os vasos foram forrados internamente com sacos plásticos para evitar a perda de água e de nutrientes pela drenagem. Para reposição da água evapotranspirada foi realizada irrigação, com água deionizada, sobre a superfície ou através de canos de PVC perfurados e introduzidos no solo, mantendo-se a umidade do solo entre 40 e $60 \%$ da capacidade de campo, sempre por meio de aferições diárias por pesagem.

Ciência Rural, v. 31, n. 6, 2001. 
As sementes receberam escarificação química com 112504 concentrado, segundo método elaborado por NICOLOSO et al. (1997), seguido de tratamento com solução fungicida à base de Benlate a $0,2 \%$ p/v. Após procedeu-se a semeadura de três sementes diretamente nos vasos. Após a emergência das plântulas, fez-se a seleção das mesmas deixando-se duas por vaso.

A análise do crescimento das plantas foi realizada mensalmente até os 140 dias, a partir da emergência, através da altura da planta, do diâmetro do caule a $1,0 \mathrm{~cm}$ do solo e do número de folhas remanescentes. Aos 140 dias após a emergência das plantas, avaliaram-se, ainda, o comprimento do sistema radicular (segundo método descrito por TENNANT, 1975), a massa seca das folhas, do caule, das raízes e do total da planta e a relação entre a massa seca das raízes e da parte aérea. A análise estatística dos resultados observados baseou-se na análise de regressão, ao nível de probabilidade de erro de $5 \%$.

\section{RESULTADOS E DISCUSSÃO}

A adubação de $\mathrm{P}$, na ausência de $\mathrm{N}$ e de $\mathrm{K}$, aumentou linearmente a altura de plantas a partir dos 60 dias após a emergência (DAR) até aos 120 DAR. Aos 140 DAE, o efeito foi quadrático estimando-se o ponto de máxima resposta acima da maior dose aplicada (Figura la). A resposta positiva e linear à aplicação de K ocorreu a partir dos 30 até os 120 DAR e tomando-se quadrática aos 140 DAR, com ponto de máxima resposta também acima da maior dose aplicada (Figura lb).

A adubação nitrogenada, quando aplicada isoladamente ou associada ao $\mathrm{P}$, não alterou a altura de plantas durante todo o período de avaliação. Entretanto, na avaliação feita aos 140 DAR, observou-se resposta quadrática para o K, com pontos de máxima eficiência técnica correspondentes a 71 e $89 \mathrm{mg}$ kgt respectivamente, paraNeK(Figura lc).

Segundo NICOLOSO et al. (1999), a altura de plantas jovens de grápia (168 dias), cultivadas em casa de vegetação, foi afetada
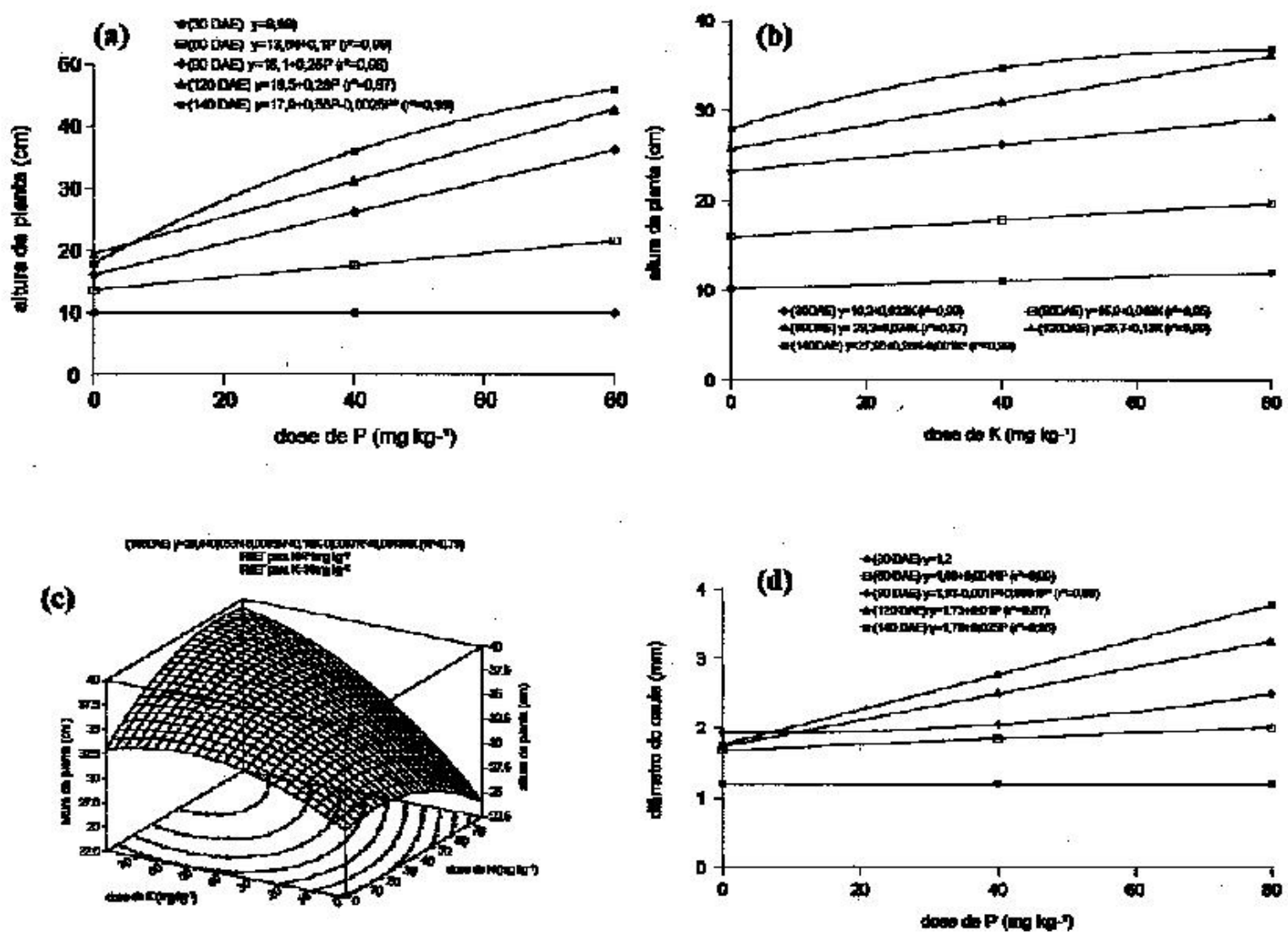

Figura 1 - Efeito da adubação isolada de P (a) e de K (b) e adubação conjunta de N e K (c) na altura de plantas e de P (c) no diâmetro do caule da grápia (Apuleia leiocarpa), aos 30, 60, 90, 120 e 140 dias após a emergência das palntas. Santa Maria, 1997.

Ciência Rural, v. 31, n. 6, 2001. 
(a)

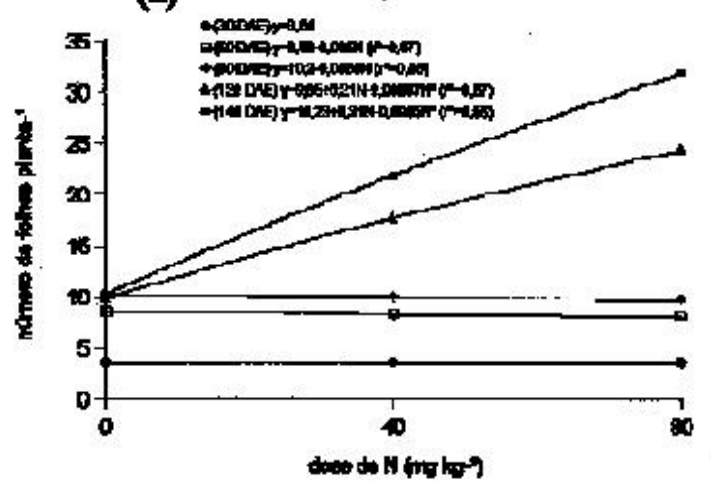

(c)

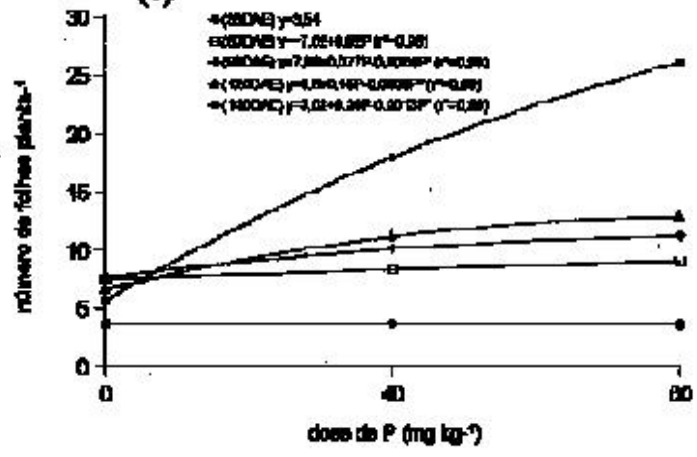

(e)

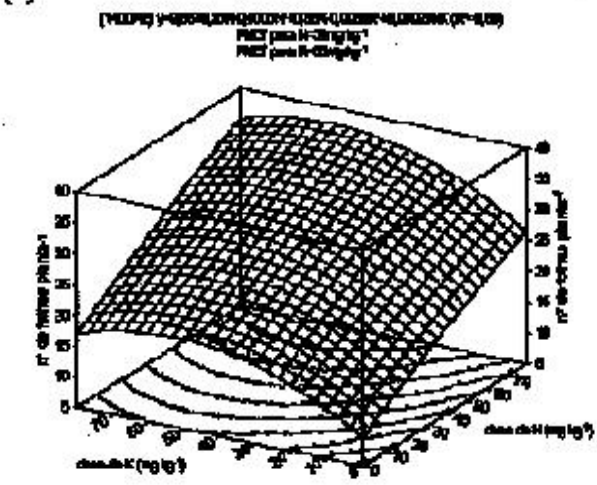

(b)

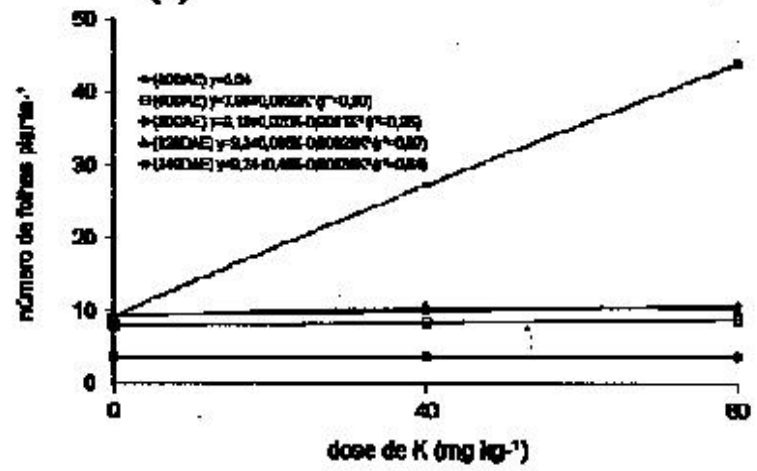

(d)

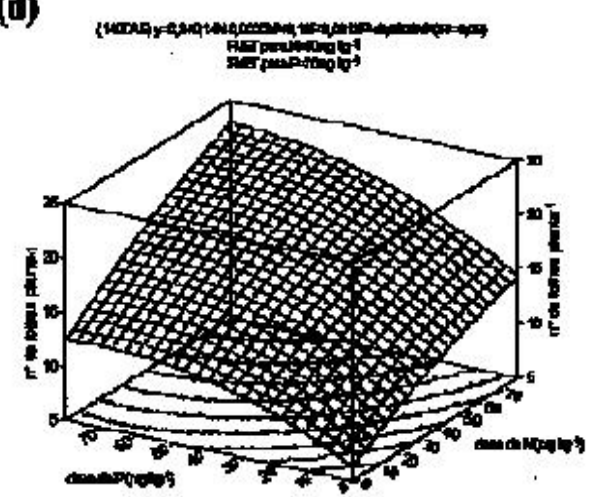

Figura 2 - Efeito da adubação isolada de N (a), de K (b), de P (c) e da adubação conjunta de N e P (d) e de N e K (e) no número de folhas de mudas de grápia (Apuleia leiocarpa Vog. Macbride), aos 30, 60, 90, 120 e 140 dias após a emergência das plantas. Santa Maria, 1997.

negativamente pela omissão isolada de $\mathrm{P}, \mathrm{N}, \mathrm{K}$ e $\mathrm{S}$ na adubação em solo ARGISSOLO VERMELHO Distrófico arênico.

Quanto ao diâmetro do caule, houve resposta significativa à apliração de $\mathrm{P}$ a partir dos 60 DAR, seguindo o modelo linear nas avaliações realizadas aos 120 e 140 DAR (Figura ld), indicando que doses maiores de $\mathrm{P}$ beneficiariam o crescimento. Resultados semelhantes, embora em outras condições de solo e clima, foram observados por VOLPATO et al. (1994), que obtiveram crescimento máximo em diâmetro do caule de seringueira (Hevea 
(a)

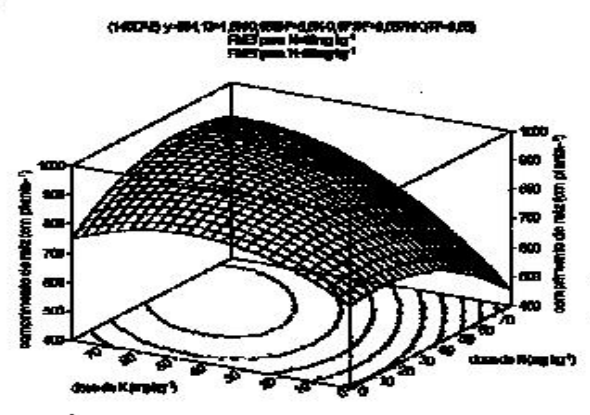

(b)

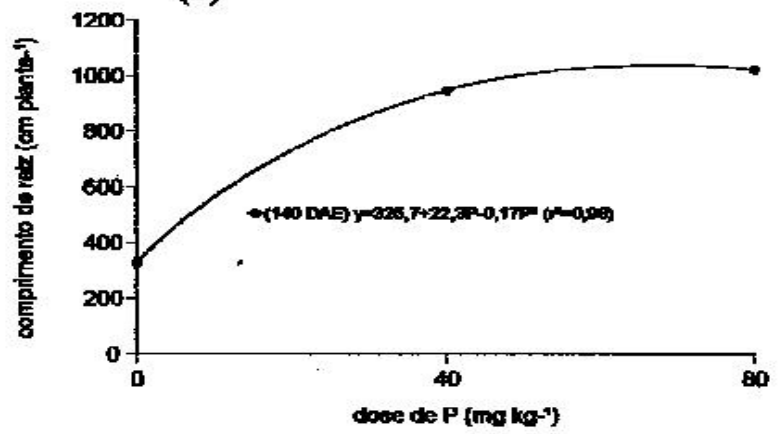

Figura 3 - Efeito da adubação conjunta de N e K (a) e da adubação isolada de P (b) no comprimento do sistema radicular de mudas de grápia (Apuleia leiocarpa Vog. Macbride), aos 140 dias após a emerg encia das plantas, Santa Maria, 1997.

spp.) pela adição de $108 \mathrm{mg}$ de $\mathrm{P}$ kg' No caso da grápia, apesar do solo apresentar teor muito baixo de K (16mg kg'), este foi suficiente para não limitar o crescimento do diâmetro do caule.

Para o número de folhas, observou-se aos 60 e 90 DAR resposta linear negativa à aplicação isolada de N, passando a quadrática dos 120 DAR aos 140 DAR (Figura 2a). Quanto à adubação potássica (Figura 2b) e fosfatada (Figura 2c), verificou-se que, na avaliação aos $60 \mathrm{DAR}$, houve resposta positiva linear da aplicação isolada destes nutrientes, sendo a partir daí até aos 140 DAR resposta quadrática. Aos 140 DAR, além da resposta quadrática à aplicação isolada de N, K e P, também se observou interação da adubação nitrogenada com a fosfatada e da nitrogenada com a potá.ssica. Os pontos críticos de máxima eficiência técnica estimada à adubação foram de 60 e $78 \mathrm{mg} \mathrm{kgt}$ res? ectivamente, para $\mathrm{N}$ e $\mathrm{P}$ (Figura $2 \mathrm{~d}$ ) e 38 e $65 \mathrm{mg}$ $\mathrm{kg}$, respectivamente, para $\mathrm{N}$ e $\mathrm{K}$ (Figura 2e). NICOLOSO et al. (1999) obtiveram resultados semelhantes em grápia, trabalhando nas mesmas condições experimentais, nos quais a omissão de $\mathrm{P}$ foi o fator que mais limitou a produção de folhas. $\mathrm{Na}$ deficiência de $\mathrm{P}$, os efeitos que mais chamam a atenção são a redução na expansão da folha e na área da superfície foliar (FREDEEN et al., 1989), bem como no número de folhas (LYNCH et al., 1991).

Quanto ao comprimento do sistema radicular, verificou-se resposta positiva à adubação nitrogenada somente quando aplicada junto ao $\mathrm{K}$, sendo as doses de máxima eficiência técnica estimada em 48 e $65 \mathrm{mg} \mathrm{kg}$, respectivamente, para $\mathrm{N}$ e K (Figura 3a). A aplicação isolada de $\mathrm{P}$ apresentou resposta quadrática, na qual a máxima eficiência técnica estimada kú em 70mg de P kg' (Figura 3b). DANIEL et al (1997), estudando a resposta de mudas de Acacia mangium à aplicação de $\mathrm{P}$ em LATOSSOLO ROXO, obtiveram resposta significativa positiva tanto no comprimento do sistema radicular como na massa seca das raízes, resultados semelhantes aos obtidos para a grápia, demonstrando a importância do $\mathrm{P}$ para o desenvolvimento das raízes.

A produção de massa seca da planta e de seus órgãos foi avaliada apenas aos 140 DAE. Observou-se para a massa seca de raiz resposta quadrãtica à aplicação isolada de $\mathrm{P}$, com ponto de máxima eficiência técnica estimada em $80 \mathrm{mg}$ de $\mathrm{P}$ kg' (Figura 4a). Considerando-se também que o comprimento do sistema radicular (Figura 3b) foi afetado negativamente pelo baixo conteúdo original de $\mathrm{P}$ do solo, sugere-se que a grápia, na fase inicial do seu desenvolvimento, é uma espécie pouco eficiente em absorver $\mathrm{P}$ quando em baixa disponibilidade no substrato. Resultados semelhantes foram obtidos por BARROS et al. (1982) em Eucalyptus ssp., pois a eficiência de absorção de $\mathrm{P}$ também foi baixa nos períodos iniciais do desenvolvimento das mudas, necessitando de teores no solo mais elevados àqueles requeridos pela maioria das outras culturas.

A massa seca do caule respondeu linearmente à aplicação isolada de $\mathrm{P}$ (Figura 4a) e K (Figura 4b). Quanto à massa seca das folhas, não se verificou resposta significativa à aplicação de $\mathrm{N}$, isoladamente ou associado ao P. Porém, junto ao K, a resposta foi quadrática (Figura $4 \mathrm{c}$ ), com ponto de máxima eficiência técnica estimada em 70 e 104mg kg', respectivamente, para N e K. Resultados semelhantes foram obtidos por VALERI et al. (1993a), que constataram resposta máxima na massa seca da parte aérea de $\boldsymbol{E}$. urophyila com $102 \mathrm{mg}$ de $\mathrm{K}$ kg', na presença de $\mathrm{N}$ a 1 10mg kgt A adubação fosfatada proporcionou resposta linear, demonstrando que doses mais elevadas beneficiariam o acúmulo de massa seca de folhas (Figura 4a). 
(a)

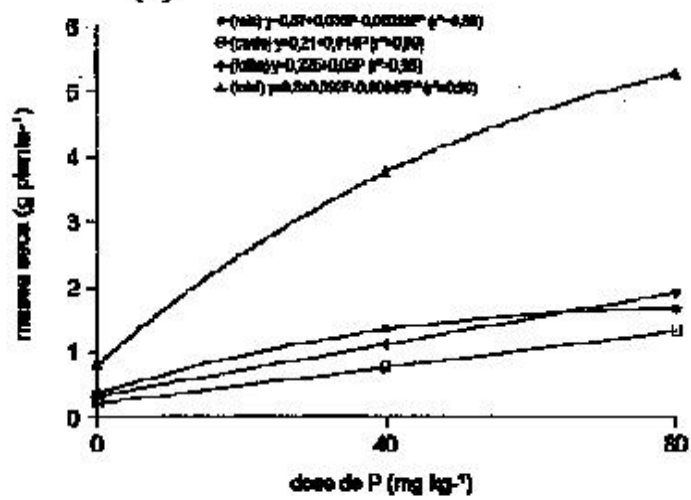

(e)

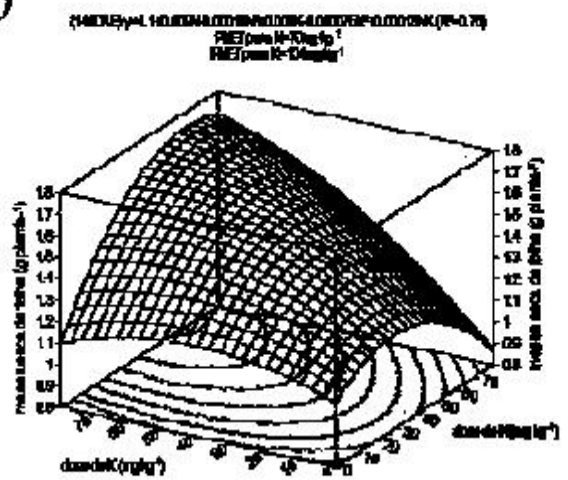

(c)

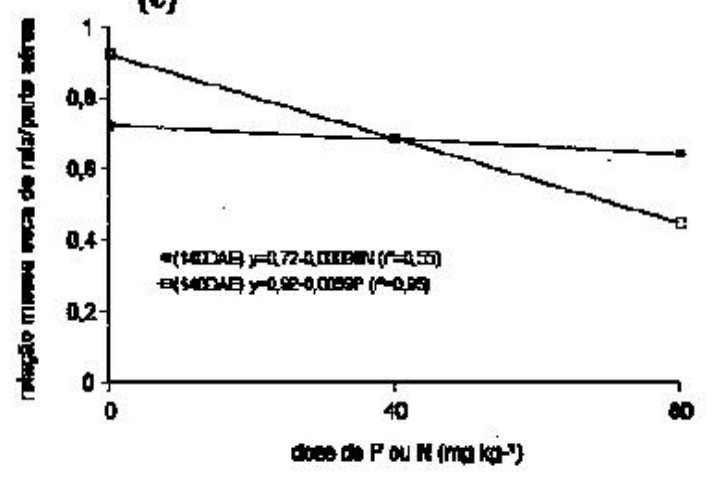

(b)

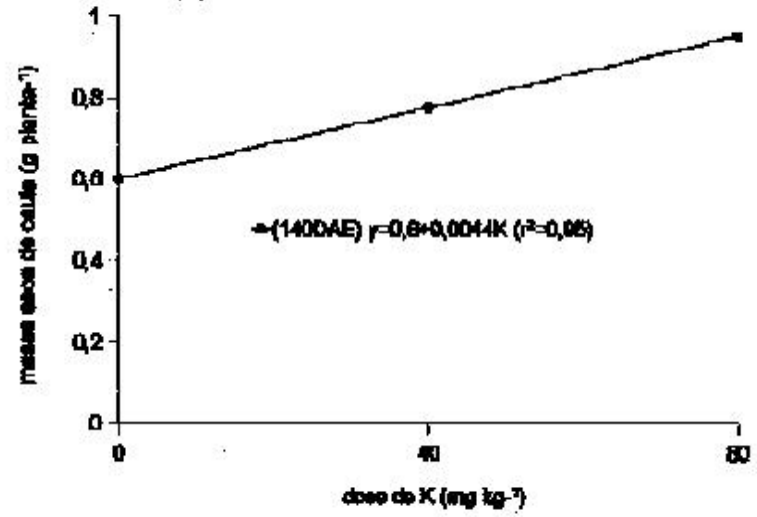

(d)

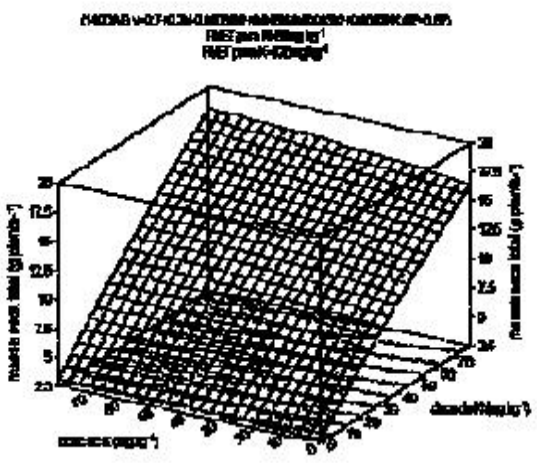

Figura 4 - Efeito da dubação isolada de P (a) na massa seca total da planta e de seus ógãos, da adubação de K (b) na massa seca de caule e da adubação conjunta de $\mathrm{N}$ e K (c) na massa seca de folhas e (d) da planta, bem como da adubação isolada de $\mathrm{N}$ e de $\mathrm{P}$ na relação da massa seca da raiz e da parte área (e) de mudas de grápia (Apuleia leiocarpa Vog. Macbride), aos 140 dias após a emergência das plantas, Santa Maria - RS.

A massa seca total da planta apresentou resposta semelhante àquela observada na massa seca das folhas, ou seja, não se verificou resposta àaplicação de $\mathrm{N}$, isoladaniente ou associado ao $\mathrm{P}$. Por outro lado, junto ao $\mathrm{K}$ proporcionou incremento significativo, sendo o ponto crítico de máxima eficiência técnica estimada em 69 e 125mg kgt respectivaniente, para N e K (Figura 4d). A aplicação isolada do $\mathrm{P}$ apresentou resposta quadrática, e a máxima resposta ficou acima da

Ciência Rural, v. 31, n. 6, 2001. 
maior dose aplicada (Figura 4a). Estes resultados corroboram em parte àqueles obtidos em Eucaiyptus grandis por VALERI et al. (1993b), que observaram aumento significativo na massa seca das plantas aos 122 dias de cultivo pela aplicação de P; por outro lado, a aplicação de $\mathrm{K}$ teve efeito positivo até a dose de SOmg kg' e o nitrogênio não proporcionou incremento.

O teor inicial de $\mathrm{P}$ (8mg kg') do solo utilizado é baixo, motivo pelo qual a adubação fosfatada aumentou a altura da planta (Figura la), o diâmetro do caule (Figura ld), o número de folhas (Figura 2c), o comprimento do sistema radicular (Figura 3b) e a massa seca total da planta e de seus ôrgãos (Figura 4a). Portanto, fica demonstrada a limitação potencial do solo ARGISSOLO VERMELHO Distrófico arênico para sustentar o cultivo da grápia sem a correção da fertilidade natural, fato já registrado por NICOLOSO et $\boldsymbol{a l}$. (1999). Estes resultados corroboram aqueles observados por BRASIL (1973) e CARVALHO (1994).

Existe grande diferença entre as espécies vegetais quanto ao nível satisfatório de $\mathrm{K}$ para o seu desenvolvimento inicial. Em um latossolo, com teor de $\mathrm{K}$ de apenas $6 \mathrm{mg}$ kg' pelo extrator Mehlich-1, NOVAIS $\boldsymbol{e t}$ al. (1979) não constataram resposta de mudas de Eucaiyptus grandis a adição de KC1. Por outro lado, NOVAIS et al (1990), revisando vários trabalhos de outros pesquisadores, consideram que o nível satisfatório deste nutriente no solo encontra-se na faixa de 40 a $60 \mathrm{mg} \mathrm{kg}$ ', para maioria das culturas anuais. Quanto à grápia, devido ao solo apresentar teor muito baixo de K (16mg kg'), observou-se benefício da adubação potássica em vários parâmetros do crescimento (Figura lb, 2b, 2e, 3a, $4 b, 4 c)$.

Observou-se que a relação entre a massa seca das raízes e da parte aérea (RIPA) apresentou decréscimo com o aumento das doses de $\mathrm{P}$ e $\mathrm{N}$ (Figura 4-e), sendo mais acentuado para o $\mathrm{P}$, em que decresceu de 0,92 para 0,45, entre as doses extremas (0 e 80mg de $\mathrm{P}$ kg'). Para o $\mathrm{N}$, a relação variou de 0,72 a 0,64 , entre $\mathrm{O}$ e $80 \mathrm{mg} \mathrm{kgt}$ respectivanlente. $\mathrm{O}$ crescimento da parte aérea sob deficiência de $\mathrm{P}$ émuito mais afetado do que o crescimento radicular, resultando no aumento da relação R/PA (MARSCHNER, 1995; DANIEL et al, 1997; NICOLOSO et ali, 1999). Segundq MARSCHNER (1995), essa resposta fisiológica está correlacionada a três fatores: (i) aumento da distribuição dos carboidratos às raízes, (ii) maior retenção do $\mathrm{P}$ absorvido nas raízes, e (iii) translocação líquida adicional de $\mathrm{P}$ da parte aérea às raízes. DANIEL $\boldsymbol{e t}$ ali (1997) registraram em mudas de Acacia mangiwn valor de 0,45 na relação $\mathrm{R} / \mathrm{PA}$ pela aplicação de $260 \mathrm{mg}$ de $\mathrm{P}$ kgt Esses autores consideram como valores ideais para a produção de mudas a serem levadas ao campo, uma relação situada entre a 0,45 e 0,50 . Sob deficiência de $\mathrm{N}$, o crescimento foliar é reduzido mais que o crescimento radicular, fato que acontece também em solos secos, salmos ou compactados (MUNNS \& CRAMER, 1996). Todavia, OLSTHOORN et al. (1991) observaram diminuição na razão R/PA com o aumento no suprimento de $\mathrm{N}$ em Pseudotsuga menziesii.

Considerando-se que, (i) ao contrário do que ocorre com o fósforo, o nível crftico de potássio no solo, para o crescimento de algumas espécies florestais, como o eucalipto (NOVAIS et al. 1990), aumenta com a idade da planta, (ii) em experimentos de vaso a relação raiz/solo é várias vezes maior da que ocorre no campo e (iii) os níveis de adubação mais elevados de $\mathrm{N}$, de $\mathrm{P}$ e de $\mathrm{K}$ utilizados foram de $80 \mathrm{mg} \mathrm{kg}$ ', as doses de máxima eficiência técnica estimadas para a adubação da grápia em ARGISSOLO VERMELHO Distrófico arênico devem ser restritas para a produção de mudas em vasos sob condições de casa de vegetação.

\section{CONCLUSÃO}

A máxima eficiência técnica estimada da adubação fosfatada e potássica na produção de massa seca da planta é acima de 80mg kg' e, para a adubação nitrogenada, de $70 m g$ kgt.

$\mathrm{O}$ efeito benéfico da adubação nitrogenada é condicionado à aplicação conjunta de potássio.

A grápia demonstra ser uma planta muito exigente em $\mathrm{P}$ e medianamente exigente em $\mathrm{K}$ e $\mathrm{N}$, na sua fase inicial de crescimento, quando cultivada em ARGISSOLO VERMELHO Distrófico arênico.

\section{REFERÊNCIAS BIBLIOGRÁFICAS}

BARROS, N.F., NOVAIS, R.F., NEVES. J.C.L.. $\boldsymbol{e t} \boldsymbol{a l}$. Interpretação de análises qufmicas de solo para o crescimento de Eucalypttu spp. Revista Árvore, Viçosa, v.6, n.1, p.38-44, 1982.

BRASIL. Levantamento de reconhecimento dos solos do Estado do Rio Grande do Sul. Recife Ministário da Agricultura - Departamento Nacional de Pesquisa Agropecuária — Divisão de Pesquisas Pedológicas, 1973. 431p. (BoletimTdcnico, 30).

CARVALHO, P.E.R. Espécies florestais brasileiras, recomnendaç(Ies silvlculturais, potencialidades e uso da madeira. Brasilia EMBRAPA-CNPFISPI, 1994. 640p. 
DANIEL, O., VITORINO, A.C.T., ALOVISI, A.A., $\boldsymbol{e} \boldsymbol{t} \boldsymbol{a l}$. Aplicação de fósforo em mudas de Acacia nangiwn WILL). Revista Árvore, Viçosa, v.21, n.2, p.163-168, 1997.

FREDEEN, AL., RAO, 1.M., TERRY, N. Infiuence of phosphorus nutrition ou growth and carbon partitioning in Gljtcuae mar. Plant Physlology, Baltimore, v.89, p.225-230, 1989.

LYNCH, J., LÀUCHLI, A, EPSTEIN, E. Vegetative growth of the common bean $\mathrm{m}$ response to phosphorus nulrition. Crop Science, Madison, v.31, p.38O-387, 1991.

MARSCHNER, $\mathrm{H}$. Mineral nutrition of higher planta. 2. $\mathrm{cd}$. London: Acadeniic, 1995. 889p.

MATTOS, N.F., GUARANHA, J. Contribuição ao estudo da gr pia (Apadeia iuiocwpa). Porto Alegre Instituto de Pesquisas de Recursos Naturais Renováveis “AP”, 1983. 25p. (Boletim Técnico. 12).

MUNNS, R., CRAMER, (3.R. Is coordination of leaf and root growth mcdiated by absicisic acid? Opinion. Plant and Sou, Netherlands, v.185, p.23-49, 1996.

NICOLOSO, F.T., GARLET, A., ZANCHETTI, F., et al. Efeito de métodos de escarificação na superação da dormência de sementes e de substratos na germinação e no desenvolvimento da gripia (Apuieia ieiocarpa). Ciência Rural. Santa Maria, v.27, n.3, p. ${ }^{4} 19-424,1997$.

NICOLOSO, F.T., ZANCHETTI, F., GARLET, A, et al. Exigências nutricionais da grápia (Apsdeia ieiocarpa Vog. Macbuide) em solo Podzólico vermelho amarelo. Ciência Rural, Santa Maria, v.29, n.2, p.225-231, 1999.
NOVAIS, R.F., GOMES. J.M., ROCHA, D. ci ai. Calagem e adubação mineral na produção de mudas de eucalipto (Eucaiyptus trandit W. HiII ex Maiden): 1-efeito da calagem e dos nutrientes N, P e K. Revista Árvore, Viçosa, v.3, p.121.134, 1979.

NOVAIS, R.F., BARROS, N.F., NEVES J.C.L Nutrição mineral do eucalipto. In: BARROS, N.F. \& NOVAIS, R.F. Relação solo-eucalipto. Viçosa: Universidade Federal de Viçosa, 1990. Cap.2. p.25-98

OLSTHOORN, AF.M., KELTJENS, W.G., van BAREN, B., $\boldsymbol{e}$ al. Infiuence ou ammonium ou fine root development and rhizosphere $\mathrm{pH}$ of Douglas-fir seedlings iii sand. Plant and Soil, Netherlands, v.133, p.75-81, 1991.

TENNANT, D.A. A Test of a nx,difled lime intersect method of estimating root lenght. Journal of Ecology, [s.1], v.63, n3, p.995-1001, 1975.

VALERI, S.V., ARAÚJO, iA., JUNIOR, LP. Efeito de nitrogenio, potássio e calagem no desenvolvimento e composição química foliar de Eacaiyptus mrophyila S.T. BLAKE cultivada sob dois regimes hídricos, $\mathrm{cm}$ casa de vegetação. In: CONGRESSO FLORESTAL BRASILEIRO, 7, 1993. Curitiba. Anais... Curitiba: SBSISBEF, 1993 V.1. 8'75p. p.249-251.

VALERI, S.V., PIRES, A.LB., BANZATTO, D.A.. et al. Efeito da adubação NPK no desenvolvimento inicial de progCmes de Eucaiyptus grandmz Hill Ex Maiden em condições de casa de vegetação. In: CONGRESSO FLORESTAL BRASILEIRO, 7, 1993, Curitiba. Anais... Curitiba : SBS/SBEF, 1993b. VI. 875p. p.246-248.

VOLPATO, MML, VENTORIM, N., ALVES, R.M.B., et al Efeitos de níveis crescentes de fósforo e zinco no desenvolvimento de porta-enxuto de seringueira (Hepea spp.). Revista Árvore, Viçosa. v18, LI, p.I4-21, 1994.

Ciência Rural, v. 31, n. 6, 2001. 